\title{
Recognition on the Relationship between Science and Technology and Table Tennis
}

\author{
Yafei Li \\ Eastern International Art College \\ Zhengzhou University of Light Industry \\ Zhengzhou, China
}

\begin{abstract}
In today's society, science and technology have penetrated into people's lives. In the field of table tennis, the development trend of diversification is becoming more and more obvious. Science and technology play a great role in promoting the evolution and development of this sport, especially in the advance of professional skills. It has a farreaching significance to use the positive energy of science and technology reasonably, develop different types of table tennis for different groups, help athletes get effective training, adjust mental and physical state and gain excellent achievements, use new scientific and technological means and equipment reasonably, better safeguard the content and spirit of sports, perfect competition rules and regulations, establish a sound supervision and inspection mechanism, and resist the negative impact of science and technology.
\end{abstract}

Keywords-modern sports; table tennis; science and technology; fairness

\section{THE RELATIONSHIP BETWEEN SCIENCE AND TECHNOLOGY AND MODERN SPORTS}

At the end of the 19th Century, there is a trend of international sports. Sports are beyond the boundaries of countries. The scientific and technological progress has promoted the development and transformation of the society. It has brought about positive influence on the production and life of human beings. At same time, it has brought some negative impacts to human beings. People feel unsafe, and pay more and more attention to it. Some people even think that human beings will be destroyed by the high degree of civilization they created. The decline of physical and physiological indexes and the exacerbation of mental load further strengthen the traditional compensatory function of sports. On the one hand, people should take part in sports broadly in order to restore the normal function of the body with physiological damage. On the other hand, it also needs to use sports and create a suitable living environment for necessary physical activity forms and establish necessary life style to ease the psychological tension. Out of physical and psychological needs, more and more people start to not allow their children to stay beside the TV or game machine. They go outside for camping, traveling, playing balls, swimming, fishing, bicycling and so on, and enjoy the fun of activities in nature. This kind of activities can not only balance their emotions, but also help them get rid of the loneliness caused by high technology to some extent. Sports socialization and entertainment and lifelong sports have reflected the several important aspects of the overall development trend of sports under scientific and technical revolution. Popular individual or collective sports in the process of sports socialization are for fitness and recreation, so some people consider the development trend of sports as sports entertainment, or simply treat modern mass sports as "entertainment sports" or "happy sports". According to the implementing forms and characteristics of entertainments, sports can be divided into several categories. The entertainment fitness class includes modern dance, family gymnastics, aerobics, artistic gymnastics, and etc. Science and technology sports become the "tonic" for body.

\section{The APPLICATION OF SCIENCE AND TECHNOLOGY IN TABLE TENNIS}

Table tennis, as China's "national ball", is the pride of 1.3 billion Chinese people. In the Olympic Games, our seeded players always can easily beat foreign players and achieve excellent results. How do Chinese athletes create miracle? Most news reports are inclined to their extraordinary talents, strict training and indomitable spirit for their success. But it is not enough just by the sports spirit and will quality. The high integration of tactics and science and technology has penetrated into every corner of the field, including equipment improvement, training of athletes, adjustment of competitive state and etc. It can be not separated from science and technology. Due to the development of science and technology, the competition is increasingly fierce and the record was refreshed over and over. For example, use the computer to carry on the "computer simulation training", to correct the takeoff and smash motion of players, and analyze the defending and attacking mode of opponent. The robot coach can serve 95 balls every minute at most with a top speed of 111 miles per hour and 11 random placement. The speed and radian are adjustable. The robot coach can design and save 50 different and continuous serves. Or it can be adjusted to random mode. The ping-pang glue is a legend. The legend of speedup glue started from 70's. It was completely unexpected. A former Yugoslavia player forgot to bring the old-type glue before the game, so the player found a bike shop beside the gym and bought some tyre cement. And then the speedup glue was born. The secret lies in that the speedup glue can soften rubber sheet, so that the holding time of racket is longer, the serve speed is faster and 
rotation is stronger. Of course, the effect only is only a few hours, so it needs to be produced on the spot. However, due to toxic element of speedup glue, it has been banned in game of young group. And after the 2008 Beijing Olympics, it was completely banned among games of the professional group.

From April 23, 2009 to April 26th, the Beijing Sporting Goods Show was held in the New International Exhibition Center. As the first sporting goods show in the inorganic era, the theme of the exhibition is "table tennis technology and life". This show perfectly displayed the far-reaching influence of science and technology on the development of table tennis. Table tennis experience area mainly consisted of DIY working table, rainbow 08 table, new serve machine, new and finished bats and some traditional products. The 3 days of exhibition attracted a large number of fans and customers. They stopped to experience, and it was the highlight of the whole table tennis hall. 2009 Beijing Sporting Goods Show has been concluded, but the smoke floated over the inorganic era is still there. The scientific and technological progress reaches to every step of new product development and promotion. It helps China hold the lead in the field of table tennis and promotes the continuous development of our table tennis.

\section{The Positive And Negative EfFects of ScIENCE AND TECHNOLOGY ON THE TABLE TENNIS}

\section{A. The Positive Influence of Science and Technology on Table Tennis}

1 ) The diversification influence of science and technology on the development of table tennis. Sports have become increasingly popular and entertainment-oriented and lifelong activities. Many table tennis enthusiasts choose more convenient and more interesting exercise mode of different form and different contents according to their own situation, such as TV table tennis derived from new media. People can play table tennis with virtual opponent and electronic rackets before screen. Many workers have less free time, and they cannot go to gym or park to play table tennis. The TV table tennis saves time and plays the function of fitness, and it needn't to invite other person. It is very convenient and interesting.

2)The development of table tennis equipment. At first table tennis balls were made of cork or rubber. Sometimes the surface is covered with light and strong wool. Around 1890, an England retired cross-country runner James Gibb accidentally discovered a celluloid hollow toy ball when he traveled to the United States. This kind of ball has strong bounce. After the celluloid ball appeared, the wooden racket took place of hollow small-net racket. The friction and elasticity of the wooden racket is small, so it can only be used to block flatly and smash straightly. The playing methods are simple and the technologies are easy. In 1902, the British Goodea invented the rubber particle racket. Its appearance and use increased flexibility and friction in hitting, resulting in the generation of rotation and chopping methods. In 1951, an Austrian invented the sponge racket. The emergence of sponge racket caused debate. In 1959, the ITTF made a decision on normalized table tennis racket: sponge + rubber sheet, thus improving the hitting speed, strength and rotation. The table tennis technique advanced from defense to attack. In the thirty-seventh session of the ITTF Congress the racket rules were first modified. (1) not allow to use the racket without covering for hitting; (2) colors of the coverings on both sides of the racket shall be obviously different; for example, one is red, and the other is dark, or corresponding to this color. This congress also passed the rule of losing score if stamping in service. It is to avoid athletes using stamping sound to cover sound of hitting with different coverings and making the opponent unable to judge the type of covering.

Since 1920's, Japanese team made a success with sponge racket. Athletes paid more and more attention to racket performance. Sponge of different performance could lead to the qualitative change of hitting. A lot of coaches and athletes study skills and tactics, at same time they consider "weapons" (rackets) as an important research task to obtain success. From the view of duplicity of thing connotation, the evolution of the racket has greatly promoted the development of table tennis. From the 90's table tennis playing field has been greatly improved, and table tennis equipment, table, tennis, baffle, score table, and ball are not single and in old-fashioned color. The new light illumination is more reasonable. These changes make the play fielding become lively, and greatly improve the view reception effect and ratings, promote the dissemination of table tennis and expand the influence of table tennis sports in the world.

\section{B. The Negative Impact of Science and Technology on the Table Tennis}

1) Deviating from the track of sports spirit. As everyone knows, sports can coordinate people's physical and mental health and gradually create a healthy body through effective exercise. Sports can help players develop strong will and achieve open inner world, which is one of the important significances of the existence of sports. For sports lovers, they are not for a title. They are really interested in spirit and value of sports, and care about the fun brought by sports. The application of science and technology in table tennis make sports commercialized and profitable. Advanced science and technology have increased the fun of table tennis, but they also put forward more requirements for activity environment. The activity place has changed from outdoor to indoor. It has changed from relative aerobic exercise into anaerobic exercise. The mode changed from double mode and multimode into single mode, which is not conducive to people's mind communication. One person plays table tennis with computer and has a rest when she/he feels tired. It can not help develop perseverance effectively and break through self stamina. Therefore, it is not good for fitness and exercise of will. Science and technology promote the diversification development of table tennis; but it, to some extent, deviates from the essence of sports spirits.

2)The competitiveness of events and the damage of fairness. Due to the use of science and technology, relatively speaking, personal professional skills and psychological qualities are weakened. People put the focus to the sophisticated equipment, and analysis of scientific data. They 
believe in science but don't believe themselves. Things are objectively being, but things are always changing. Superiors fight against superiors not only by professional skills but also will quality. Too much emphasis on objective data and ignoring the subjective spirit are very foolish. Science and technology promote the diversification development of table tennis. However, entertainment of table tennis is superior to competitiveness of table tennis. If things go on like this, only a few people master professional table tennis skills. It is very unfavorable to the development of table tennis. Due to unevenness in technological development level among countries, the foundation platform of competition is not in the same level. It is very unfair to athletes.

3)The use of drugs, harming athletes' physical and mental health. Use different types and different doses of banned drugs, and the extent of damage to the human body is not the same. Generally speaking, there is a serious change in personality. It may result in drug dependence and allergic reactions, lead to abnormality of cell and organ function, and damage immunity and cause various infections. Of particular concern is that many harmful effects are only showed a few years later, and even doctors can not tell which athletes are in danger, which will not be a problem temporarily. Psychologically speaking, the use of stimulants is immoral. Athletes using stimulants is a deception. The use of stimulants will cause a great harm to people's physical and psychological health. It seriously harms people's physical and mental health.

\section{CONCLUSIONS}

\section{A. The Development of Table Tennis to Meet the Needs of All Kinds of People}

Adolescents and children are in an important period of the development of physical and mental health. It is good to self-growth and the cultivation of personal will quality to promote competitive table tennis. In the competing process, they communicate with each other. It is of great significance to the cultivation of personality and character. The middleaged people often have a great life and work pressure. They can choose recreational table tennis without physical contact, such as machine game and other types. They can relax themselves and exercise their body. The aged people have relative low stamina, and they can choose extended and enlarged racket and shortened table for playing table tennis, which is very good for the aged people's physical and mental health.

\section{B. Promoting the Sports Spirit and Keeping the Original Color of Sports}

It takes ten years to grow a tree and a hundred years to bring up a generation of good men. Reasonably use science and technology and start training from childhood. Advocate outdoor sports, communicative sports and competitive sports, reduce the negative impact of science and technology in table tennis as far as possible, and keep the original color of sports, and thus exercise the body, develop the will and shape and improve the human personality. Schools should vigorously promote table tennis and advocate professional table tennis skills and tough sports spirit in ensuring the competitiveness and entertainment.

\section{Severely Punishing Violations and Vicious Competition, Improving the Rules and Reasonably Using the Positive Energy of Science and Technology}

Sports competition is dual contest of professional skills and the spirit of the individual. Today, the competitive sports are seriously commercialized and profitable. Competition authorities often become a target for all. To maintain "fairness and justice" of contest, we should keep pace with the times, further improve the rules of various competitions with advanced ideas and advanced technology means, and strengthen supervision. To completely reverse the situation of "fair furnishing and money orientation" in sports competition, we should explore the reasons in a wide range. If the contests of sports become the contest of science and technology, it is completely contrary to the essence of sports. For example, the use of various stimulants emerge in an endlessly. It not only harms the health of athletes and seriously undermines the fairness and justice of sports morality, but also pollutes the social atmosphere, contributing to the opportunistic, irregular and even illegal means. China's attitude to stimulants is the "three strict policy" - "strict prohibition, strict inspection and strict treatment". From a deeper level, the sports authorities should take the original spirit and content as the purpose, and clearly regulate the use content, way and degree of science and technology in sports competitions. Individual and organization against rules and regulations should be given seriously punishment. And the authorities should reasonably use the positive energy of science and technology, and promote the healthy development of table tennis.

\section{REFERENCES}

[1] Liu Jianhe. Table Tennis Sport and Training. Beijing: People's Sports Press, 2004.

[2] Su Piren. Table Tennis Sport. Beijing: Higher Education Press, 2004.

[3] Wang Jisheng. Exploration on Table Tennis Racket. Beijing: People's Education Press, 2005.

[4] Cheng Xu. Innovation and Development of Table Tennis. Journal of Wuhan Sports Institute, 2000, 34 (5): 47-49.

[5] A'ying Ga, Wang Yu. Dialectical View on the Influence of Science and Technology Progress on Competitive Sports. Sports Culture Guide, 2006 (9): 23-25.

[6] Tang Dongyang. The Influence of Science and Technology on the Development of Table Tennis. Culture and History Expo, 2007 (6): 66-67. 